\title{
Relationships of Chronic Kidney Disease and Thyroid Dysfunction in Non-Dialysis Patients: A Pilot Study
}

\author{
Binbin Pan ${ }^{a} \quad$ Xin Du ${ }^{a}$ Hao Zhang ${ }^{a}$ Xi Hua ${ }^{a}$ Xin Wan ${ }^{a}$ \\ Changchun $\mathrm{CaO}^{\mathrm{b}}$ \\ aDepartment of Nephrology, Nanjing First Hospital, Nanjing Medical University, \\ Nanjing, PR China; ${ }^{b}$ Department of Nephrology, Sir Run Run Hospital, Nanjing Medical \\ University, Nanjing, PR China
}

\section{Keywords}

Euthyroid sick syndrome $\cdot$ Chronic kidney disease $\cdot$ Anemia $\cdot$ C-reactive protein $\cdot$ Albumin

\begin{abstract}
Context: Patients with chronic kidney disease (CKD) usually manifest with disorder of thyroid hormone; however, the correlation is unknown. Objective: The study was designed to explore the relationships between CKD and thyroid dysfunction. Design, Setting, and Participants: A total number of 905 non-dialysis participants were collected at Nanjing First Hospital from August 2009 to October 2012 according to the case records system. Patients were grouped via the estimated glomerular filtration rate (eGFR) according to the KDIGO guideline. Levels of thyroid hormone and biomarkers in different CKD groups were compared by ANOVA. Prevalence of different thyroid diseases was calculated by $\chi^{2}$ test. Results: We found that FT3 or T3 became more prevalent with increasing eGFR with the lowest level in CKD5 $(p<0.01)$. No significant differences were found between groups in FT4, T4, or TSH $(p>0.05)$. Frequency of euthyroid sick syndrome (ESS) in CKD groups was high, especially in CKD stage 5 (69.1\%, $p<$ 0.01). eGFR had positive correlation with T3 and FT3 $(r=0.239, p=0.0001 ; r=0.292, p=$ $0.0001)$. ESS had correlations with prealbumin, $\beta 2$-microglobin, eGFR, and $C$-reactive protein $(r=0.095, p=0.004 ; r=-0.12, p=0.001 ; r=0.091, p=0.007 ; r=-0.096, p=0.008 ; r=0.154$, $p=0.001)$. After adjustment for prealbumin, uric acid, HbA1c, age, gender, eGFR, and $\beta 2-$ microglobin, binary regression revealed that hemoglobin, $C$-reactive protein, and albumin were independent influence factors of ESS ( $p=0.016, r=1.014 ; p=0.023, r=1.007 ; p=0.029$, $r=0.996$ ). Conclusion: CKD patients have a high morbidity of ESS, mainly low T3 syndrome. Anemia, inflammation, and malnutrition may contribute to ESS in CKD.
\end{abstract}

B.P. and X.D. contributed equally to this work. 


\section{Kidney \\ Blood Pressure \\ Research}

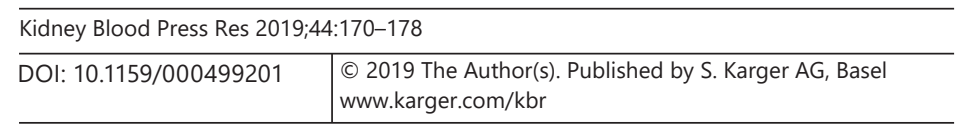

Pan et al.: Chronic Kidney Disease and Thyroid Dysfunction

\section{Introduction}

The prevalence of chronic kidney disease (CKD) in China was 10.8\% [1]. Clinically, disorders of the thyroid gland such as hypothyroidism and euthyroid sick syndrome (ESS) often occur in CKD patients, especially in CKD stage 5 [2-4]. Patients with hypothyroidism can have clinically important reductions in estimated glomerular filtration rate (eGFR), which can be attenuated by using thyroid hormone replacement therapy [5, 6]. Hypothyroidism can also lead to hyperlipoidemia and atherosclerosis in coronary and peripheral vessels. Studies indicated that subclinical and clinical hypothyroidism were the risk factors for all-cause mortality and CVD death [7-9]. Similar to hypothyroidism, ESS was associated with endothelial dysfunction in stage 3 and 4 CKD patients [10], as well as with cardiomyopathy [11] and a high risk of death in CKD stage 5 .

A study [2] has indicated that the prevalence of subclinical primary hypothyroidism increased from $5.4 \%$ at an estimated GFR $>90 \mathrm{~mL} / \mathrm{min} / 1.73 \mathrm{~m}^{2}$ to more than $20 \%$ at an estimated GFR $<60 \mathrm{~mL} / \mathrm{min} / 1.73 \mathrm{~m}^{2}$. In addition, Song and his fellows [3] showed high morbidity of low T3 in CKD patients. However, the mechanistic link and directionality of the association between ESS and kidney disease remain widely unknown. Inflammatory cytokines and oxidative stress may play pivotal roles in the pathogenesis of ESS in patients with CKD. Our previous study suggested that albuminuria is an independent risk factor of T4 elevation in CKD [12]. However, albuminuria is not the unique cause of CKD. Therefore, it is essential to assess probable risk factors for ESS in CKD.

It is well known that CKD can induce a number of complications and comorbidities. No data to date are available about the relationships of thyroid hormone and eGFR, gender, age, uric acid, hemoglobin ( $\mathrm{Hb}$ ), albumin, and C-reactive protein (CRP) in CKD patients. Hence, we conducted the study to explore the relationships between thyroid hormone and biomarkers in CKD patients and ascertain risk factors for ESS.

\section{Materials and Methods}

A total of 905 non-dialysis patients hospitalized with CKD from August 2009 to October 2012 were registered via the case records system of Nanjing First Hospital. We excluded subjects who were younger than 18 years, women who were pregnant (given potential pregnancy-related changes in thyroid function), subjects who were receiving concurrent treatment with drugs that could affect thyroid function (lithium, amiodarone, iodine, methimazole, or propylthiouracil), and patients with acute kidney injury. The study was performed in accordance with the Declaration of Helsinki and was approved by the Institutional Review Board of Nanjing First Hospital (IRB No. 86-025-52271039-21). Informed consent was obtained from all participants when they were admitted to the hospital.

\section{Laboratory Measure}

Thyroid function was tested by using electrochemiluminescence assay (Siemens, Centaur $\mathrm{XP}$ ) at the second day of admission. The normal reference range in our institute for TSH was 0.55-4.78 mIU/L, T4 (TT4) 58.1-140.6 nmol/L, FT4 11.5-22.7 pmol/L, T3 (TT3) 0.92-2.79 $\mathrm{nmol} / \mathrm{L}$, and FT3 3.5-6.5 pmol/L. Clinical hyperthyroidism was defined as decreased TSH with increased FT4, TT4 and/or FT3, TT3; clinical hypothyroidism was defined as increased TSH with decreased FT4 and decreased or normal FT3; subclinical hyperthyroidism was defined as decreased TSH with normal FT4, TT4, FT3, TT3; subclinical hypothyroidism was defined as increased TSH with normal FT4, TT4 and/or FT3, TT3; ESS was defined as normal or decreased TSH with decreased FT3, TT3 and/or lower FT4, TT4. 
Table 1. Characteristics of subjects in different CKD groups according to eGFR

\begin{tabular}{|c|c|c|c|c|c|}
\hline Characteristics & CKD1 & CKD2 & CKD3 & CKD4 & CKD5 \\
\hline Male/female & $96 / 143$ & $75 / 75$ & $81 / 56$ & $149 / 133$ & $41 / 56$ \\
\hline Cystatin C, mg/L & $0.99 \pm 0.24$ & $1.37 \pm 0.29$ & $1.79 \pm 0.37$ & $2.86 \pm 0.90$ & $4.44 \pm 1.49^{*}$ \\
\hline ß2-microglobin, mg/L & $2.17 \pm 0.7$ & $3.50 \pm 3.84$ & $4.12 \pm 1.28$ & $7.57 \pm 4.25$ & $14.34 \pm 4.29^{*}$ \\
\hline $\mathrm{Scr}, \mu \mathrm{mol} / \mathrm{L}$ & $60.15 \pm 12.27$ & $86.61 \pm 15.85$ & $114.83 \pm 17.74$ & $197.05 \pm 56.1$ & $511 \pm 267.98^{*}$ \\
\hline eGFR, $\mathrm{mL} / \mathrm{min}$ & $110 \pm 14$ & $75 \pm 11$ & $53 \pm 5$ & $29 \pm 9$ & $10 \pm 4 *$ \\
\hline Uric, $\mu \mathrm{mol} / \mathrm{L}$ & $292.38 \pm 107.1$ & $359.5 \pm 123.1$ & $433.8 \pm 126.3$ & $485.3 \pm 129.2$ & $512.1 \pm 162.3^{*}$ \\
\hline $\mathrm{ACR}, \mathrm{mg} / \mathrm{g}$ & $158.46 \pm 325^{*}$ & $334.69 \pm 584.4$ & $283.89 \pm 405.6$ & $466.89 \pm 644.2$ & $982.28 \pm 1,881$ \\
\hline $\mathrm{Hb}$ & $131.7 \pm 17.44$ & $127.9 \pm 19.55$ & $121.68 \pm 19.22$ & $107.51 \pm 19.24$ & $87.62 \pm 15.51 *$ \\
\hline Albumin & $35.94 \pm 6.93$ & $35.66 \pm 6.90$ & $36.66 \pm 5.88$ & $35.54 \pm 5.27$ & $32.66 \pm 4.80^{*}$ \\
\hline Prealbumin & $188.13 \pm 59.16$ & $184.35 \pm 69.3$ & $201.97 \pm 63.46$ & $199.41 \pm 78.56$ & $193.22 \pm 78.29$ \\
\hline CRP & $15.69 \pm 38.07$ & $17.87 \pm 38.53$ & $14.11 \pm 32.1$ & $19.76 \pm 36.83$ & $32.04 \pm 66.7^{\#}$ \\
\hline HbA1c & $6.28 \pm 1.58$ & $6.29 \pm 0.99$ & $6.16 \pm 1.04$ & $6.25 \pm 1.20$ & $5.78 \pm 1.14^{\#}$ \\
\hline Age & $52.68 \pm 15.48^{*}$ & $66.21 \pm 15.4$ & $70.9 \pm 12.29$ & $71.78 \pm 13.61$ & $70.55 \pm 15.52$ \\
\hline FT3, pmol/L & $3.69 \pm 0.85$ & $3.39 \pm 0.85$ & $3.35 \pm 0.81$ & $3.12 \pm 1.06$ & $2.68 \pm 0.69 *$ \\
\hline T3, nmol/L & $1.2 \pm 0.4$ & $1.1 \pm 0.4$ & $1.1 \pm 0.4$ & $1.0 \pm 0.5$ & $0.8 \pm 0.3^{*}$ \\
\hline FT4, pmol/L & $8.49 \pm 7.56$ & $9.50 \pm 7.74$ & $8.78 \pm 7.16$ & $9.23 \pm 7.21$ & $8.99 \pm 6.73$ \\
\hline $\mathrm{T} 4, \mathrm{nmol} / \mathrm{L}$ & $56.25 \pm 50.58$ & $61.01 \pm 52.2$ & $52.36 \pm 49.36$ & $57.14 \pm 47$ & $60.58 \pm 44.3$ \\
\hline TSH, mIU/L & $3.02 \pm 2.96$ & $4.43 \pm 11.6$ & $3.60 \pm 5.07$ & $4.28 \pm 13$ & $2.61 \pm 2.09$ \\
\hline
\end{tabular}

ACR, urinary albumin-to-creatinine ratio; Scr, serum creatinine; eGFR, estimated glomerular filtration rate (CKD-EPI fourlevel race equation). ${ }^{*} p<0.05,{ }^{*} p<0.01$.

Serum creatinine (Scr), cystatin C, uric acid, $\beta 2$-microglobin, albumin, and prealbumin were measured by OLYMPUS AU5400 automatic biochemical analyzer (Olympus Corporation, Mishima, Japan). The calibrators for the enzymatic method were traceable to an isotope dilution mass spectrometric method for Scr using standard reference methods NIST SRM 967 [13]. Hb was detected by Sysmex XT-1800i Automated Hematology System (Shanghai, China). The concentrations of serum CRP was measured using electrochemiluminescence by ELECSYS 2010 (Roche, Switzerland). HbA1c was determined using the BioRad VARIANT II HPLC analyzer (Biorad, Hemel Hempstead, UK). eGFR was calculated by the Chronic Kidney Disease Epidemiology Collaboration (CKD-EPI) four-level race equation [14, 15] and the last Scr value before discharge was selected as the baseline level. The specific CKD-EPI four-level race GFR estimation equation is shown in Table 1.

\section{Statistical Analysis}

Statistics analysis was performed by PASW 18.0 statistical software (SPSS Inc., Chicago, IL, USA). The expressions of eGFR equation in PASW were as follows:

eGFR $=\operatorname{EXP}(\operatorname{LN}(151)-0.328 \times \operatorname{LN}(\mathrm{Scr} / 88.4 / 0.7)+$ age $\times$ LN $(0.993))$ (if female and creatinine $<0.7)$;

eGFR = EXP $($ LN (151) $-1.210 \times \operatorname{LN}($ Scr/88.4/0.7) + age $\times$ LN (0.993)) (if female and creatinine $\geq 0.7)$;

eGFR = EXP (LN (149) $-0.412 \times$ LN (Scr/88.4/0.9) + age $\times$ LN (0.993)) (if male and creatinine <0.9);

eGFR $=\operatorname{EXP}(\operatorname{LN}(149)-1.210 \times \operatorname{LN}(\mathrm{Scr} / 88.4 / 0.9)+$ age $\times$ LN (0.993)) (if male and creatinine $\geq 0.9$ ).

CKD stages were defined in accordance with KIDGO guideline: stage 1,24-hour proteinuria $>0.15 \mathrm{~g}$ with eGFR $\geq 90 \mathrm{~mL} / \mathrm{min} / 1.73 \mathrm{~m}^{2}$; stage 2,24 -hour proteinuria $>0.15 \mathrm{~g}$ with $60 \mathrm{~mL} /$ 
Fig. 1. The mean and $95 \% \mathrm{CI}$ of FT3 in CKD stage. CKD stage 1: eGFR $\geq 90 \mathrm{~mL} / \mathrm{min}$; CKD stage 2 : $90 \mathrm{~mL} / \mathrm{min}>\mathrm{eGFR} \geq 60 \mathrm{~mL} / \mathrm{min}$; CKD stage $3: 30 \mathrm{~mL} / \mathrm{min}>\mathrm{eGFR} \geq$ $60 \mathrm{~mL} / \mathrm{min}$; CKD stage $4: 15 \mathrm{~mL} /$ $\min >\mathrm{eGFR} \geq 30 \mathrm{~mL} / \mathrm{min}$; CKD stage 5: eGFR $<15 \mathrm{~mL} / \mathrm{min}$; $\mathrm{CI}$, confidence interval; FT3, free T3 (pmol/L).

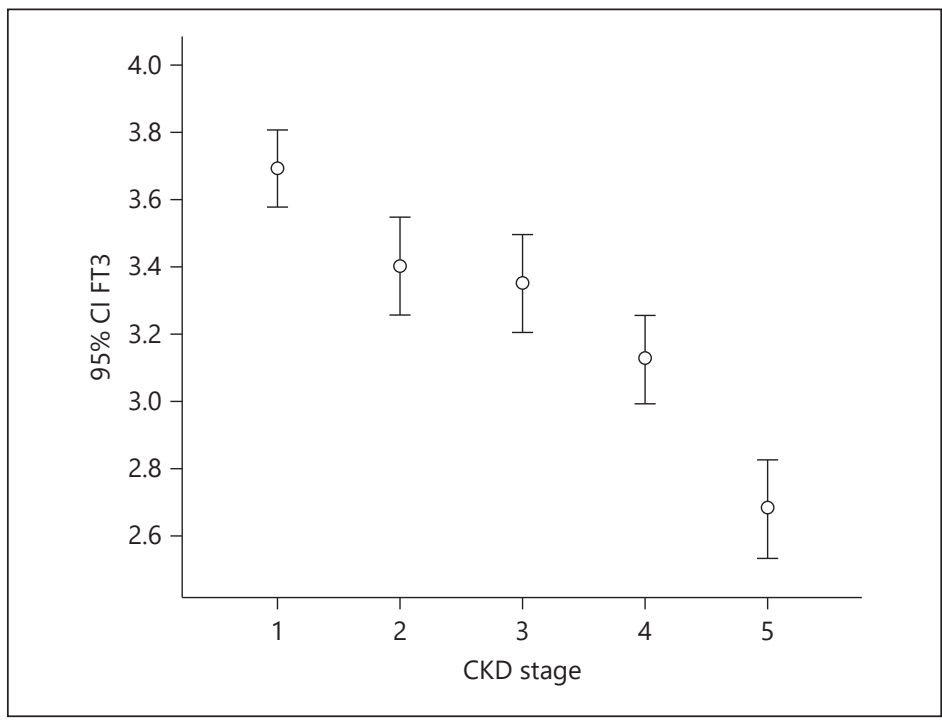

$\mathrm{min} / 1.73 \mathrm{~m}^{2} \leq \mathrm{eGFR}<90 \mathrm{~mL} / \mathrm{min} / 1.73 \mathrm{~m}^{2}$; stage $3,30 \mathrm{~mL} / \mathrm{min} / 1.73 \mathrm{~m}^{2} \leq \mathrm{eGFR}<60 \mathrm{~mL} /$ $\mathrm{min} / 1.73 \mathrm{~m}^{2}$; stage $4,15 \mathrm{~mL} / \mathrm{min} / 1.73 \mathrm{~m}^{2} \leq \mathrm{eGFR}<30 \mathrm{~mL} / \mathrm{min} / 1.73 \mathrm{~m}^{2}$; stage 5 , eGFR $<15$ $\mathrm{mL} / \mathrm{min} / 1.73 \mathrm{~m}^{2}$.

Data were expressed as mean \pm SD. Prevalence of different thyroid diseases was calculated by $\chi^{2}$ test. Levels of thyroid hormone and other biochemical markers in different CKD stages were compared using one-way ANOVA. The correlations between thyroid hormone and biomarkers were analyzed by Spearman correlation analysis. Additionally, binary regression was employed to explore risk factors for ESS. $p$ values $<0.05$ were considered to be statistically significant.

\section{Results}

Characteristics of Subjects in Different CKD Groups

There were significant differences among the five groups in cystatin $C, \beta 2$-microglobin, Scr, and eGFR $(p<0.01)$. Levels of uric acid and ACR in CKD4 and CKD5 were markedly higher than those in other groups $(p<0.01)$, while anemia in CKD4 and CKD5 was more severe than that in CKD1-CKD3 $(p<0.01)$. CKD5 populations had lower albumin and higher CRP than other stages ( $p<0.01$ and $p<0.05$ ); however, the level of prealbumin revealed no significant difference between CKD5 and other groups. HbA1c in CKD5 showed significantly lower levels than CKD1, CKD2, and CKD4 ( $p<0.05)$. Age in CKD1 group was significantly lower than other groups $(p<0.01)$. FT3 or T3 became more prevalent with increasing eGFR with the lowest level in CKD5 ( $p<0.01$, Fig. 1 and 2). No significant differences were found between groups in FT4, T4, or TSH $(p>0.05)$ (Table 1$)$.

\section{The Prevalence of Different Thyroidism in Each CKD Group}

Hyperthyroidism and subclinical hyperthyroidism were rare in CKD patients. However, high prevalence of hypothyroidism and subclinical hypothyroidism was shown in the CKD population. Moreover, morbidity of ESS in CKD revealed extremely high, especially in CKD stage $5(69.1 \%, p<0.01)$. (Table 2$)$. 
Fig. 2. The mean and $95 \% \mathrm{CI}$ of T3 in CKD stage. CKD stage 1: eGFR $\geq 90 \mathrm{~mL} / \mathrm{min}$; CKD stage 2: 90 $\mathrm{mL} / \mathrm{min}>\mathrm{eGFR} \geq 60 \mathrm{~mL} / \mathrm{min}$; CKD stage $3: 30 \mathrm{~mL} / \mathrm{min}>\mathrm{eGFR} \geq$ $60 \mathrm{~mL} / \mathrm{min}$; CKD stage 4: $15 \mathrm{~mL} /$ $\min >$ eGFR $\geq 30 \mathrm{~mL} / \mathrm{min}$; CKD stage 5: eGFR $<15 \mathrm{~mL} / \mathrm{min}$; $\mathrm{CI}$, confidence interval; T3, total T3 (nmol/L).

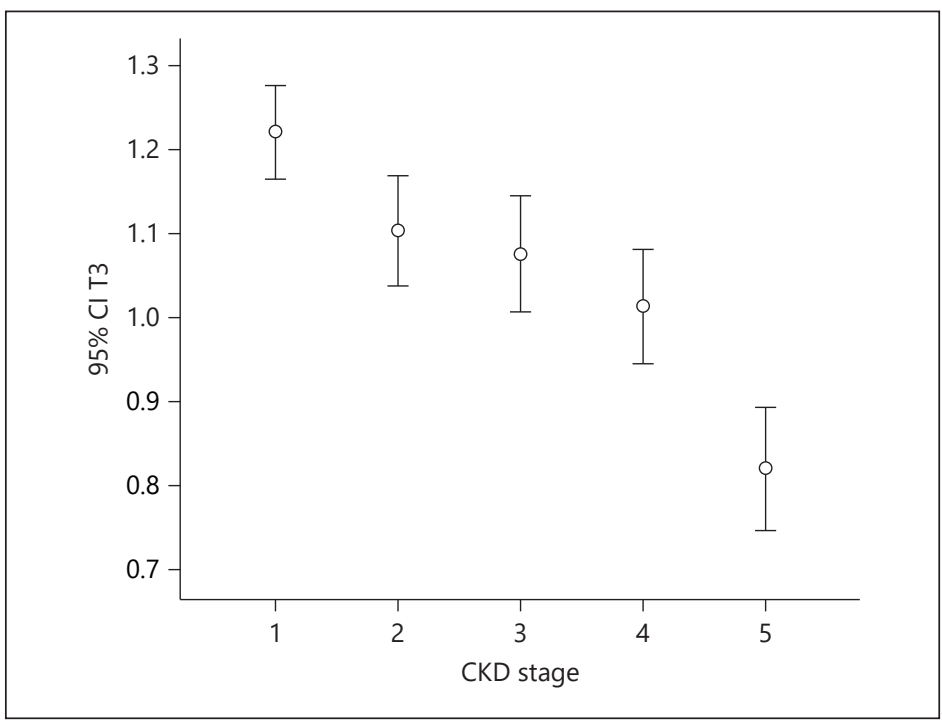

Table 2. The prevalence of different types of thyroidism in each CKD group

\begin{tabular}{llllrr}
\hline $\begin{array}{l}\text { Estimated GFR, mL/ } \\
\text { min/1.73 } \mathrm{m}^{2}\end{array}$ & Hyperthyroidism & Hypothyroidism & $\begin{array}{l}\text { Subclinical } \\
\text { hyperthyroidism }\end{array}$ & $\begin{array}{l}\text { Subclinical } \\
\text { hypothyroidism }\end{array}$ & $\begin{array}{l}\text { Euthyroid sick } \\
\text { syndrome }\end{array}$ \\
\hline$\geq 90$ & $3(1.3 \%)$ & $20(8.4 \%)$ & $3(1.3 \%)$ & $13(5.4 \%)$ & $141(59 \%)$ \\
$60-89$ & 0 & $18(12 \%)$ & $2(1.3 \%)$ & $13(8.7 \%)$ & $81(54 \%)$ \\
$30-59$ & 0 & $12(8.8 \%)$ & 0 & $13(9.5 \%)$ & $80(58.4 \%)$ \\
$15-29$ & 0 & $26(9.2 \%)$ & $2(0.7 \%)$ & $10(3.5 \%)$ & $175(62.1 \%)$ \\
$<15$ & $2(2.1 \%)$ & $5(5.2 \%)$ & 0 & $8(8.2 \%)$ & $67(69.1 \%)^{*}$ \\
\hline
\end{tabular}

$* p<0.01$.

\section{Correlation Analysis of Thyroid Hormone and Biomarkers}

The scatterplot of eGFR associated with FT3 is shown in Figure 3. Pearson correlation coefficient $(r$ ) was $0.239, p=0.0001$, indicating that FT3 was significantly positively correlated with eGFR. The scatterplot of T3 associated with eGFR is revealed in Figure 4. Pearson correlation coefficient $(r)$ was $0.292, p=0.0001$, suggesting that T3 was significantly positively correlated with eGFR. ESS had correlations with prealbumin, $\beta 2$-microglobin, eGFR, and CRP $(r=0.095, p=0.004 ; r=-0.12, p=0.001 ; r=0.091, p=0.007 ; r=-0.096, p=0.008$; $r=0.154, p=0.001$ ). After adjustment for prealbumin, uric acid, HbA1c, age, gender, eGFR, and $\beta 2$-microglobin, binary regression revealed that $\mathrm{Hb}, \mathrm{CRP}$, and albumin were independent influence factors of ESS ( $p=0.016, r=1.014 ; p=0.023, r=1.007 ; p=0.029, r=0.996)$.

\section{Discussion}

Our study revealed that level of T3 and FT3 decreased in accordance with eGFR. eGFR had positive correlation with T3 and FT3 by Pearson correlation analysis. The most common disorder of thyroid gland in CKD is ESS. In our study, we found that CKD patients had a rising trend in frequency of ESS and 69.1\% patients in CKD5 had ESS. Correlation analysis showed that eGFR had a positive relationship with T3 and FT3. Additionally, ESS had correlations with 
Fig. 3. Scatter plot of FT3 associated with eGFR. Smoothed line shows the fit of the data. FT3, free T3 (pmol/L); eGFR, estimated glomerular filtration rate.
Fig. 4. Scatter plot of T3 associated with eGFR. Smoothed line shows the fit of the data. T3, total T3 (nmol/L); eGFR, estimated glomerular filtration rate.
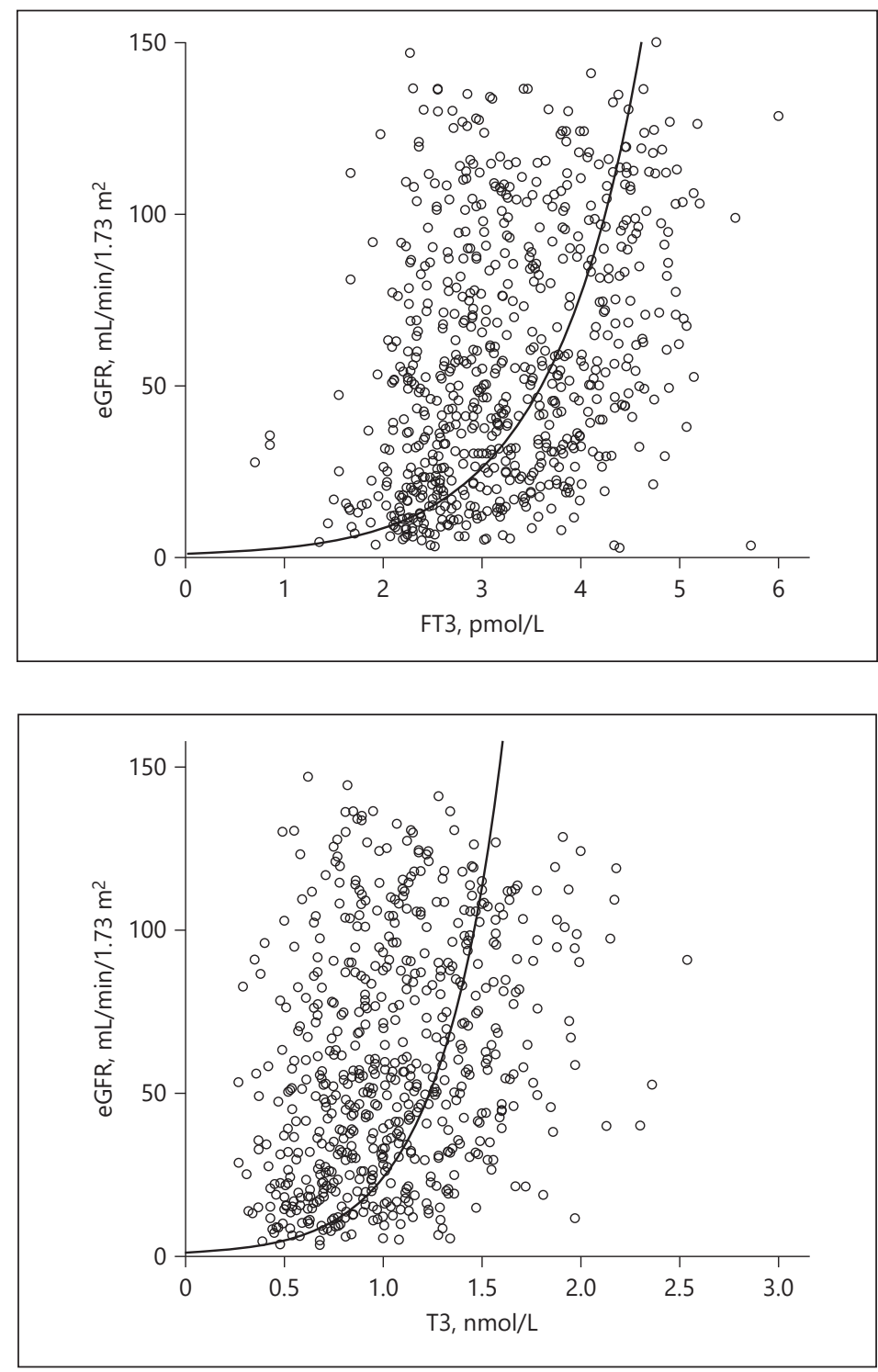

AKP, prealbumin, $\beta 2$-microglobin, eGFR, and CRP. However, binary regression only indicated that $\mathrm{Hb}, \mathrm{CRP}$, and albumin were independent influence factors of ESS.

It has been reported that kidney had a close relationship with thyroid gland [16-18]. Thyroid hormones are essential for the development and metabolism of kidney or other organs [19]. Dysfunction of thyroid gland may induce disorders of water, electrolyte, lipid, and so on. den Hollander et al. [20] reported that the thyroidal status influences kidney function both during embryonic development and the maturation of the kidney, indirectly by affecting the cardiovascular system through its influence on renal blood flow, and directly by affecting glomerular function, tubular secretion and absorptive capacities, electrolyte pumps, and kidney structure. In a micropuncture study, a $65 \%$ or higher increase in isotonic fluid reabsorption was observed in proximal tubules of thyroidectomized rats after treatment with T3 $[21,22]$. Studies indicated that hyperthyroidism increased GFR by up to $18 \%$ in hyperthyroid rats and humans $[20,23]$. Hyperthyroidism can lead to decrease in Scr and elevated cystatin C [24]. Inversely, decline in eGFR was more common in patients with overt or 


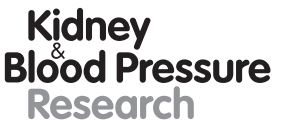

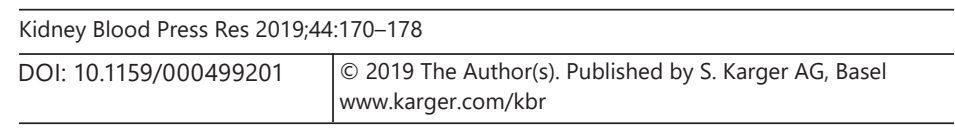

Pan et al.: Chronic Kidney Disease and Thyroid Dysfunction

subclinical hypothyroidism $[20,23,25]$. In our study, a linear relationship was shown between eGFR and T3 or FT3, which indicated that T3 or FT3 decreased with the decline in eGFR. This reduction in $\mathrm{T} 3$ concentrations has been linked to a decrease in the peripheral synthesis of T3 from T4. Although free and total T4 concentrations may be normal or slightly reduced, sometimes free T4 may be high due to the effect of heparin used in anticoagulation during hemodialysis, which inhibits T4 binding to its binding proteins [26]. This kind of change in thyroid hormone may be attributed to self-protection during severe disease to diminish basic metabolism, but the underlying mechanisms remain unknown.

Some studies $[2,3]$ predicted that CKD may lead to higher prevalence of ESS or hypothyroidism. Song and his fellows [3] showed an increasing trend for population of low T3 according to the increase in CKD stage with normal level of TSH (eGFR $\geq 90,8.2 \%$; $60 \leq$ eGFR $<90,10.9 \%$; $30 \leq$ eGFR < 60, 20.8\%; $15 \leq$ eGFR < 30, 60.6\%; eGFR <15, 78.6\%). Similar to previous studies, a big proportion of CKD $4-5$ patients also had ESS (62.1 and 69.1\%). Meanwhile, low T3 syndrome now is used as a marker of severe disease. Carrero et al. [27] indicated that low T3 levels are independent predictors of all-cause and also cardiovascular disease mortality in euthyroid patients, perhaps due to an intimate association with inflammation. Our study also revealed elevation of CRP in CKD population with the highest level in CKD5, which was broadly consistent with previous reports of elevated levels of inflammatory markers in patients undergoing hemodialysis [28-30], and in earlier stages of CKD [31, 32]. Therefore, high level of inflammation in CKD patients, especially in CKD5, may induce frequency of ESS. The regression analysis also indicated CRP was an independent risk factor of ESS.

In CKD4-5 stage, patients usually have symptoms of nausea, vomiting, bad appetite because of accumulation of toxin, and anemia. Therefore, it is common to observe malnutrition in the CKD population, especially at the CKD5 stage. In our study, the level of albumin in CKD5 was $32.66 \pm 4.80 \mathrm{~g} / \mathrm{L}$, which was significantly lower than in the other groups. Additionally, $\mathrm{Hb}$ went down with the decrease in GFR in accordance with usual pathophysiology. Hence, hypoalbumin and severe anemia contributed to the high prevalence of ESS.

The limitation of our studies was one single center, which may lead to crowd bias; however, nearly all kinds of diseases that may lead to CKD were included; therefore the result was believable.

Taken together, our study showed that people with CKD had a high prevalence of ESS, mainly low T3 syndrome. Anemia, inflammation, and malnutrition may contribute to ESS in CKD.

\section{Disclosure Statement}

The authors have nothing to disclose.

\section{Funding Sources}

This work was supported by grants from Chinese Society of Nephrology (14050430580), the Foundation of Science and Technology Development Program, Nanjing Medical University (2011NJMU195, 2012NJMU233), Jiangsu Provincial Special Program of Medical Science (BL2014015), the Key Medical Talent Training Program of the Jiangsu Province Health Bureau (RC2011018). The funders had no role in study design, data collection and analysis, decision to publish, or preparation of the manuscript. 


\section{Kidney \\ Blood Pressure \\ Research}

\begin{tabular}{l|l}
\hline Kidney Blood Press Res 2019;44:170-178 \\
\hline DOI: 10.1159/000499201 & $\begin{array}{l}\text { @ 2019 The Author(s). Published by S. Karger AG, Basel } \\
\text { www.karger.com/kbr }\end{array}$ \\
\hline
\end{tabular}

Pan et al.: Chronic Kidney Disease and Thyroid Dysfunction

\section{Author Contributions}

The research was designed by B.P., X.D., and C.C. All authors helped to write the report and commented on the manuscript. B.P. and X.D. analyzed the data and advised on statistical issues at the time of the research write-up. C.C. was the research administrator, obtained the data, and prepared communications with participating centers and the data monitoring committee. H.Z., X.H., and X.W. were research nurses responsible for recruitment and return of data.

\section{References}

1 Zhang L, Wang F, Wang L, Wang W, Liu B, Liu J, et al. Prevalence of chronic kidney disease in China: a crosssectional survey. Lancet. 2012 Mar;379(9818):815-22.

2 Lo JC, Chertow GM, Go AS, Hsu CY. Increased prevalence of subclinical and clinical hypothyroidism in persons with chronic kidney disease. Kidney Int. 2005 Mar;67(3):1047-52.

3 Song SH, Kwak IS, Lee DW, Kang YH, Seong EY, Park JS. The prevalence of low triiodothyronine according to the stage of chronic kidney disease in subjects with a normal thyroid-stimulating hormone. Nephrol Dial Transplant. 2009 May;24(5):1534-8.

4 Zoccali C, Mallamaci F, Tripepi G, Cutrupi S, Pizzini P. Low triiodothyronine and survival in end-stage renal disease. Kidney Int. 2006 Aug;70(3):523-8.

5 Shin DH, Lee MJ, Lee HS, Oh HJ, Ko KI, Kim CH, et al. Thyroid hormone replacement therapy attenuates the decline of renal function in chronic kidney disease patients with subclinical hypothyroidism. Thyroid. 2013 Jun;23(6):654-61.

6 Hataya Y, Igarashi S, Yamashita T, Komatsu Y. Thyroid hormone replacement therapy for primary hypothyroidism leads to significant improvement of renal function in chronic kidney disease patients. Clin Exp Nephrol. 2013 Aug;17(4):525-31.

7 Tseng FY, Lin WY, Lin CC, Lee LT, Li TC, Sung PK, et al. Subclinical hypothyroidism is associated with increased risk for all-cause and cardiovascular mortality in adults. J Am Coll Cardiol. 2012 Aug;60(8):730-7.

8 Marfella R, Carella C, Paolisso G. Subclinical hypothyroidism and cardiovascular disease. Arch Intern Med. 2012 Oct;172(19):1523-4.

9 Rotondi M, Magri F, Chiovato L. Risk of coronary heart disease and mortality for adults with subclinical hypothyroidism. JAMA. 2010 Dec;304(22):2481.

10 Yilmaz MI, Sonmez A, Karaman M, Ay SA, Saglam M, Yaman H, et al. Low triiodothyronine alters flow-mediated vasodilatation in advanced nondiabetic kidney disease. Am J Nephrol. 2011;33(1):25-32.

11 Zoccali C, Benedetto F, Mallamaci F, Tripepi G, Cutrupi S, Pizzini P, et al. Low triiodothyronine and cardiomyopathy in patients with end-stage renal disease. J Hypertens. 2006 Oct;24(10):2039-46.

12 Du X, Pan B, Li W, Zou Y, Hua X, Huang W, et al. Albuminuria is an independent risk factor of T4 elevation in chronic kidney disease. Sci Rep. 2017 Jan;7(1):41302.

13 Dodder NG, Tai SS, Sniegoski LT, Zhang NF, Welch MJ. Certification of creatinine in a human serum reference material by GC-MS and LC-MS. Clin Chem. 2007 Sep;53(9):1694-9.

14 Du X, Liu L, Hu B, Wang F, Wan X, Jiang L, et al. Is the Chronic Kidney Disease Epidemiology Collaboration fourlevel race equation better than the cystatin C equation? Nephrology (Carlton). 2012 May;17(4):407-14.

15 Stevens LA, Claybon MA, Schmid CH, Chen J, Horio M, Imai E, et al. Evaluation of the Chronic Kidney Disease Epidemiology Collaboration equation for estimating the glomerular filtration rate in multiple ethnicities. Kidney Int. 2011 Mar;79(5):555-62.

16 Feinstein EI, Kaptein EM, Nicoloff JT, Massry SG. Thyroid function in patients with nephrotic syndrome and normal renal function. Am J Nephrol. 1982;2(2):70-6.

17 Kaptein EM, Quion-Verde H, Massry SG. Hemodynamic effects of thyroid hormone. Contrib Nephrol. 1984;41: 151-9.

18 Kaptein EM. Thyroid function in renal failure. Contrib Nephrol. 1986;50:64-72.

19 Capasso G, De Santo NG, Kinne R. Thyroid hormones and renal transport: cellular and biochemical aspects. Kidney Int. 1987 Oct;32(4):443-51.

20 den Hollander JG, Wulkan RW, Mantel MJ, Berghout A. Correlation between severity of thyroid dysfunction and renal function. Clin Endocrinol (Oxf). 2005 Apr;62(4):423-7.

21 Katz AI, Lindheimer MD. Renal sodium- and potassium-activated adenosine triphosphatase and sodium reabsorption in the hypothyroid rat. J Clin Invest. 1973 Apr;52(4):796-804.

22 Capasso G, Kinne-Saffran E, De Santo NG, Kinne R. Regulation of volume reabsorption by thyroid hormones in the proximal tubule of rat: minor role of luminal sodium permeability. Pflugers Arch. 1985 Jan;403(1):97-104.

23 Capasso G, Lin JT, De Santo NG, Kinne R. Short term effect of low doses of tri-iodothyronine on proximal tubular membrane Na-K-ATPase and potassium permeability in thyroidectomized rats. Pflugers Arch. 1985 Jan;403(1):90-6. 
24 Fricker M, Wiesli P, Brändle M, Schwegler B, Schmid C. Impact of thyroid dysfunction on serum cystatin C. Kidney Int. 2003 May;63(5):1944-7.

25 Capasso G, De Tommaso G, Pica A, Anastasio P, Capasso J, Kinne R, et al. Effects of thyroid hormones on heart and kidney functions. Miner Electrolyte Metab. 1999 Jan-Apr;25(1-2):56-64.

26 Silverberg DS, Ulan RA, Fawcett DM, Dossetor JB, Grace M, Bettcher K. Effects of chronic hemodialysis on thyroid function in chronic renal failure. Can Med Assoc J. 1973 Aug;109(4):282-6.

27 Carrero JJ, Qureshi AR, Axelsson J, Yilmaz MI, Rehnmark S, Witt MR, et al. Clinical and biochemical implications of low thyroid hormone levels (total and free forms) in euthyroid patients with chronic kidney disease.J Intern Med. 2007 Dec;262(6):690-701.

28 Wanner C, Zimmermann J, Schwedler S, Metzger T. Inflammation and cardiovascular risk in dialysis patients. Kidney Int Suppl. 2002 May;80(80):99-102.

29 Honda H, Qureshi AR, Heimbürger O, Barany P, Wang K, Pecoits-Filho R, et al. Serum albumin, C-reactive protein, interleukin 6 , and fetuin a as predictors of malnutrition, cardiovascular disease, and mortality in patients with ESRD. Am J Kidney Dis. 2006 Jan;47(1):139-48.

30 Rao M, Guo D, Perianayagam MC, Tighiouart H, Jaber BL, Pereira BJ, et al. Plasma interleukin-6 predicts cardiovascular mortality in hemodialysis patients. Am J Kidney Dis. 2005 Feb;45(2):324-33.

31 Menon V, Greene T, Wang X, Pereira AA, Marcovina SM, Beck GJ, et al. C-reactive protein and albumin as predictors of all-cause and cardiovascular mortality in chronic kidney disease. Kidney Int. 2005 Aug;68(2): 766-72.

32 Barreto DV, Barreto FC, Liabeuf S, Temmar M, Lemke HD, Tribouilloy C, et al.; European Uremic Toxin Work Group (EUTox). Plasma interleukin-6 is independently associated with mortality in both hemodialysis and pre-dialysis patients with chronic kidney disease. Kidney Int. 2010 Mar;77(6):550-6. 